\title{
Parametric optimization of CNC end milling using entropy measurement technique combined with grey-Taguchi method
}

\author{
${ }^{1}$ Sanjit Moshat, ${ }^{2 *}$ Saurav Datta, ${ }^{3}$ Asish Bandyopadhyay and ${ }^{4}$ Pradip Kumar Pal \\ ${ }^{1,3,4}$ Department of Mechanical Engineering, Jadavpur University, Kolkata- 700032, West Bengal, INDIA \\ ${ }^{2}$ Department of Mechanical Engineering, National Institute of Technology (NIT), Rourkela, Orissa-769008, INDIA \\ "Corresponding Author (e-mail: sdattaju@gmail.com, Saurav Datta)
}

\begin{abstract}
End milling is the most important milling operation, widely used in most of the manufacturing industries due to its capability of producing complex geometric surfaces with reasonable accuracy and surface finish. However, with the inventions of CNC milling machine, the flexibility has been adopted along with versatility in end milling process. In order to build up a bridge between quality and productivity and to achieve the same in an economic way, the present study highlights optimization of CNC end milling process parameters to provide good surface finish and high material removal rate (MRR). The surface finish of the machined surface has been identified as quality attribute whereas MRR has been treated as performance index directly related to productivity. Attempt has been made to optimize quality and productivity in a manner that these multi-criterions could be fulfilled simultaneously up to the expected level. This has invited a multi-objective optimization problem which has been solved by Taguchi method coupled with grey relational analysis. Depending on relative importance, the priority weights of individual quality and performance attributes have been estimated by entropy measurement technique. Multi-objectives related to quality and productivity has been accumulated to evaluate an equivalent single quality index (called grey relational grade); which has been optimized finally by Taguchi method. Application feasibility of the aforesaid optimization technique has been illustrated in this reporting.
\end{abstract}

Keywords: CNC end milling, surface finish, material removal rate (MRR), entropy measurement technique, Taguchi method

\section{Introduction}

Among different types of milling processes, end milling is one of the most vital and common metal cutting operations used for machining parts because of its capability to remove materials at faster rate with a reasonably good surface quality. Also, it is capable of producing a variety of configurations using milling cutter. In recent times, computer numerically controlled (CNC) machine tools have been adopted to make the milling process fully automated. It provides greater improvements in productivity, increases the quality of the machined parts and requires less operator input. For these reasons, CNC end milling process has been recently proved to be very versatile and useful machining operation in most of the modern manufacturing industries. Only the implementation of automation in end milling process is not the last achievement. It is also necessary to improve the machining process and machining performances continuously for effective machining and also for the fulfillment of requirements of the industries.

Surface roughness is a key factor in the machining process while considering machining performance and that is why in many cases, industries are looking for maintaining the good surface quality of the machined parts. Surface roughness is a measure of the technological quality of a product and a factor that greatly influences manufacturing cost and quality. It describes the geometry of the machined surface and combined with the surface texture, it can play an important role on the operational characteristics of the part. It also influences several functional attributes of a part, such as light reflection, heat transmission, coating characteristics, surface friction, fatigue resistance etc. However, the mechanism behind the formation of surface roughness is very dynamic, complicated and process dependent; therefore it is very difficult to calculate its value through analytical formulae. Various theoretical models that have been proposed are not accurate enough and apply only to a limited range of processes and cutting 
conditions. Therefore, machine operators usually use "trial and error" approaches to set-up milling machine cutting conditions in order to achieve the desired surface roughness. Obviously, the "trial and error" method is not effective and efficient. Also, this method is very much time consuming. Therefore, the dynamic nature and widespread usage of milling operations in practice have raised a need for seeking a systematic approach that can help to set-up milling operations and also to help in achieving the desired surface roughness quality.

On the other hand, material removal rate (MRR), which indicates processing time of the work piece, is another important factor that greatly influences production rate and cost. It is also necessary to study the material removal rate along with surface roughness in CNC end milling process. So, as a whole, there is a need for a tool that will allow the evaluation of the surface roughness and material removal rate (MRR) before the machining of the part and which, at the same time, can be easily used in the productionfloor environment for contributing to the minimization of required time and cost and the production of desired surface quality. Both the surface roughness and material removal rate greatly vary with the change of cutting process parameters. That is why proper selection of cutting process parameters is also essential along with its prediction to obtain good surface finish (lower $R_{a}$ value) and higher material removal rate in $\mathrm{CNC}$ end milling process.

\section{Prior state of art and motivation of the present work}

Alauddin et al. (1995) developed two mathematical polynomial models in end milling of 190 BHN steel considering the factors: cutting speed, feed and axial depth of cut. Response surface contours were constructed based on these models. Baek et al. (1997) suggested that both static and dynamic variables of the milling process should be included in the surface roughness model. In the research made by Fuh and $\mathrm{Wu}$ (1995), Analysis of variance (ANOVA) method was adopted in order to determine the most influential parameters concerning surface quality. It was shown that the tool nose radius and feed influence surface roughness. Lee et al. (2001) developed simulation algorithms to predict the machined surface in end milling. Tsai et al. (1999) used neural networks for in-process prediction of surface roughness in milling operations. They had considered spindle speed, feed, depth of cut, and vibration "intensity" per revolution as parameters which would influence surface roughness. Benardos and Vosniakos (2002) used a neural network modeling approach for the prediction of surface roughness $\left(R_{a}\right)$ in CNC face milling. Ozcelik and Bayramoglu (2006) developed a statistical model for surface roughness estimation in a high-speed flat end milling process under wet cutting conditions, using machining variables such as spindle speed, feed rate, depth of cut, and step over. Back et al. (2001) studied the effects of the insert run-out errors and the variation of the feed rate on the surface roughness and the dimensional accuracy in a face-milling operation using a surface roughness model. Alauddin et al. (1997) presented a study of the development of mathematical models for tool life in end milling steel (190 BHN) using high-speed steel slot drills under dry conditions. Yang and Chen (2001) demonstrated a systematic procedure of using Taguchi parameter design in process control of individual milling machines. The Taguchi parameter design had been done in order to identify the optimum surface roughness performance with a particular combination of cutting parameters in an end-milling operation.

Ghani et al. (2004) applied Taguchi optimization methodology to optimize cutting parameters in end milling while machining hardened steel with TiN coated carbide insert tool under semi-finishing and finishing conditions of high speed cutting considering the milling parameters: cutting speed, feed rate and depth of cut. From the analysis of the result, the optimal combination of process parameters for low resultant cutting force and good surface finish was determined.

Mansour and Abdalla (2002) developed a surface roughness model for the end milling EN32M (a semi-free cutting carbon casehardening steel with improved merchantability). Reddy et al. (2006) investigated the role of solid lubricant assisted machining with graphite and molybdenum disulphide lubricants on surface quality, cutting forces and specific energy while machining AISI 1045 steel using cutting tools of different tool geometry (radial rake angle and nose radius). Colak et al. (2007) used genetic expression programming method for predicting surface roughness of milling surface under varying cutting parameters. Cutting speed, feed and depth of cut of end milling operations were collected for predicting surface roughness. A linear equation was predicted for surface roughness estimation in this study.

Oktem et al. (2005) focused on the development of an effective methodology to determine the optimum cutting conditions leading to minimum surface roughness in milling of mold surfaces by coupling Response Surface Methodology (RSM) with a developed genetic algorithm (GA). RSM was utilized to create an efficient analytical model for surface roughness in terms of cutting parameters: feed, cutting speed, axial depth of cut, radial depth of cut and machining tolerance.

Fuh and Chang (1997) presented a dimensional-accuracy model for the peripheral milling of aluminum alloys under dry and downmilling conditions. Bayoumi,

Kopac and Krajnik (2007) had presented the robust design of flank milling parameters dealing with the optimization of the cutting forces, milled surface roughness and the material removal rate (MRR) in the machining of an Al-alloy casting plate for injection moulds.

In end milling, surface finish and material removal rate are two important aspects, which require attention and both are to be controlled precisely, because these two factors greatly influence machining performances. In modern industry, one of the trends is to manufacture low cost, high quality products in short time. Automated and flexible manufacturing systems are employed for that purpose. CNC machines are considered most suitable in flexible manufacturing system. Above all, CNC milling machine is very 
useful for both its flexibility and versatility. These machines are capable of achieving reasonable accuracy and surface finish. Processing time is also very low as compared to some of the conventional machining process.

Surface roughness is a measure of the technological quality of a product and a factor that greatly influences manufacturing cost and quality. On the other hand, material removal rate (MRR), which indicates processing time of the work piece, is another important factor that greatly influences production rate and cost. So, there is a need for a tool that will allow the evaluation of the surface roughness and material removal rate (MRR) value before the machining of the part and which, at the same time, can easily be used in the production-floor environment contributing to the minimization of required time and cost and the production of desired surface quality. Both the surface roughness and material removal rate greatly vary with the change of cutting process parameters. That is why proper selection of process parameters is also essential along with the prediction of the surface finish (lower $\mathrm{R}_{\mathrm{a}}$ value) and material removal rate in $\mathrm{CNC}$ end milling process.

Literature depicts that previous investigators focused on various aspects of modeling and simulation of surface roughness in various milling operations. Predictive models were developed to represent correlations among surface roughness and various milling parameters. Compared to surface roughness, study on MRR has been found done to a limited extent. Parametric optimization of milling process responses have been addressed too. But it has been observed that optimization has highlighted a single objective function. In a multi-response process, it may happen that optimization of a single response may cause severe quality loss for rest of the responses. Therefore, for solving a multi-criteria optimization problem; it is advised to convert individual objectives into an equivalent single objective function. In doing so, individual response weights have to be assigned depending on their relative importance. It seems that there is no specific guideline for assignment of individual response weights. It entirely depends on the decision maker. This may change the optimal setting in the case where optimization methodology that is being adopted is sensitive. In view of the above consideration the present study has been dealt with application of grey-Taguchi method for optimization of surface roughness and MRR in end milling operation; with adaptation to entropy measurement technique to evaluate priority value (weight) of individual responses; which is based on statistical analysis of the experimental data.

\section{Experimental setup and procedure:}

Details of experimental plan are given below.

a) Checking and preparing the Vertical $\mathrm{CNC}$ milling machine system ready for performing the machining operation.

b) Preparing rectangular aluminum plates of size $95 \mathrm{~mm} \times 75 \mathrm{~mm} \times 10 \mathrm{~mm}$ in shaping machine for performing CNC end milling.

c) Calculating weight of each plate by the high precision digital balance meter before machining.

d) Creating CNC part programs for tool paths with specific commands using different levels of spindle speed, feed and depth of cut and then performing end milling operation.

e) Calculating weight of each machined plate again by the digital balance meter.

f) Measuring surface roughness and surface profile with the help of a portable stylus-type profilometer, Talysurf (Taylor Hobson, Surtronic 3+, UK)

The present experimental work seeks to evaluate the optimal result for selection of spindle speed (S), feed rate $(f)$ and depth of cut $(d)$ in order to achieve good surface roughness $\left(\mathrm{R}_{\mathrm{a}}\right.$ value) and high material removal rate (MRR) during the CNC end milling process. Table 1 represents selected process control parameters used during the experiments. These parameters have been allowed to vary in three different levels.

Table 1: Process control parameters and their limits

\begin{tabular}{cccc}
\hline Coded levels & $\begin{array}{c}\text { Spindle speed, } \\
(\mathrm{rpm})\end{array}$ & $\begin{array}{c}\text { Feed rate, } f \\
(\mathrm{~mm} / \mathrm{min})\end{array}$ & $\begin{array}{c}\text { Depth of cut, } d \\
(\mathrm{~mm})\end{array}$ \\
\hline-1 & 300 & 30 & 0.2 \\
0 & 450 & 50 & 0.5 \\
+1 & 600 & 70 & 0.8 \\
\hline
\end{tabular}

The values of coded and actual value of each parameter used in this work are listed in Table 1. The experimental design matrix adopted as per Taguchi's $\mathrm{L}_{9}$ Orthogonal Array (OA) design. The coded number for variables, used in Table 1 is obtained from the following transformation equations:

Spindle speed: $\quad A=\frac{S-S_{0}}{\Delta S}$ 
Feed rate:

$$
\begin{aligned}
& B=\frac{f-f_{0}}{\Delta f} \\
& C=\frac{d-d_{0}}{\Delta d}
\end{aligned}
$$

Depth of cut:

Here A, B and C are the coded values of the variables $\mathrm{S}, f$ and $d$ respectively; $\mathrm{S}_{0}, f_{0}$ and $d_{0}$ are the values of spindle speed, feed rate and depth of cut at zero level; $\Delta \mathrm{S}, \Delta f$ and $\Delta d$ are the units or intervals of variation in $\mathrm{S}, f$ and $d$ respectively.

The machine used for the milling is a 'DYNA V4.5' CNC vertical milling machine having the control system SINUMERIK 802 $\mathrm{D}$ with a vertical milling head. For generating the milled surfaces, CNC part programs for tool paths have been created with specific commands. The photograph of DYNA V4.5 CNC milling machine has been shown in Figure 1. The compressed coolant servo-cut has been used as cutting environment.

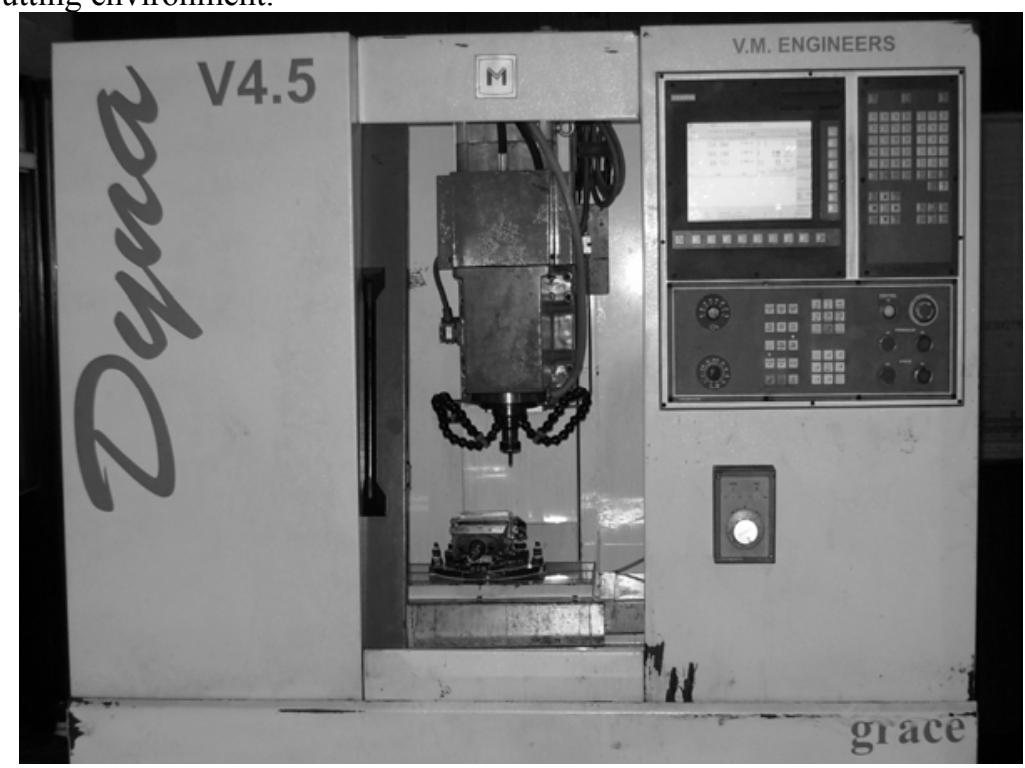

Figure 1: CNC vertical milling machine used for experiment

Commercially available CVD coated carbide tools have been used. The tools used are flat end mill cutters produced by WIDIA (EM-TiAlN). The tools are coated with TiAlN coating. For each material a new cutter of same specification has been used. The details of the end milling cutter are given below:

Cutter diameter $=8 \mathrm{~mm}$

Overall length $=108 \mathrm{~mm}$

Fluted length $=38 \mathrm{~mm}$

Helix angle $=30^{\circ}$

Hardness $=1570 \mathrm{HV}$

Density $=14.5 \mathrm{~g} / \mathrm{cc}$

Transverse rupture strength $=3800 \mathrm{~N} / \mathrm{mm}^{2}$

The test work pieces are made of Aluminum of size $95 \mathrm{~mm}$ x $75 \mathrm{~mm}$ x $10 \mathrm{~mm}$ rectangular plate. Different plates of same dimension and material are used for each experimental run. Material properties are given below:

Density: $2600-2800 \mathrm{~kg} / \mathrm{m}^{3}$

Melting Point: $660^{\circ} \mathrm{C}$

Elastic Modulus: $70-79 \mathrm{GPa}$

Tensile Strength: 230-570 $\mathrm{MPa}$

Yield Strength: 215-505 $\mathrm{MPa}$

Roughness measurement has been done using a portable stylus-type profilometer, Talysurf (Taylor Hobson, Surtronic 3+, UK).

Material removal rate (MRR) has been calculated from the difference of weight of work piece before and after experiment. 


$$
M R R=\frac{W_{i}-W_{f}}{\rho_{s} t} m m^{3} \cdot \mathrm{min}^{-1}
$$

Here, $W_{i}$ is the initial weight of work piece in $g ; W_{f}$ is the final weight of work piece in $g$; $t$ is the machining time in minutes; $\rho_{\mathrm{s}}$ is the density of aluminum $\left(2.7 \times 10^{-3} \mathrm{~g} / \mathrm{mm}^{3}\right)$.

The weight of the work piece has been measured in a high precision digital balance meter (Model: DHD - 200 Macro single pan DIGITAL reading electrically operated analytical balance made by Dhona Instruments), which can measure up to the accuracy of $10^{-4} \mathrm{~g}$ and thus eliminates the possibility of large error while calculating material removal rate (MRR) in CNC end milling process.

\section{Taguchi method}

Taguchi's philosophy, developed by Dr. Genichi Taguchi, is an efficient tool for the design of high quality manufacturing system. It is a method based on Orthogonal Array (OA) experiments, which provides much-reduced variance for the experiment resulting optimum setting of process control parameters. Orthogonal Array provides a set of well-balanced experimental settings (with less number of experimental runs), and Taguchi's Signal-to-Noise ratios (S/N), which are logarithmic functions of desired output; serve as objective functions in the optimization process. This technique helps in data analysis and prediction of optimum results. In order to evaluate optimal parameter settings, Taguchi method uses a statistical measure of performance called signal-tonoise ratio. The $\mathrm{S} / \mathrm{N}$ ratio takes both the mean and the variability into account. The $\mathrm{S} / \mathrm{N}$ ratio is the ratio of the mean (Signal) to the standard deviation (Noise). The ratio depends on the quality characteristics of the product/process to be optimized. The standard S/N ratios generally used are as follows: - Nominal-is-Best (NB), Lower-the-Better (LB) and Higher-the-Better (HB). The optimal setting is the parameter combination, which has the highest $\mathrm{S} / \mathrm{N}$ ratio, [Mahapatra and Chaturvedi (2009), Moshat et al. (2010)].

\section{Grey relational analysis}

In grey relational analysis, experimental data i.e. measured features of quality characteristics of the product are first normalized ranging from zero to one. This process is known as grey relational generation. Next, based on normalized experimental data, grey relational coefficient is calculated to represent the correlation between the desired and actual experimental data. Then overall grey relational grade is determined by averaging the grey relational coefficient corresponding to selected responses. The overall performance characteristic of the multiple response process depends on the calculated grey relational grade. This approach converts a multiple- response- process optimization problem into a single response optimization situation; the single objective function is the overall grey relational grade. The optimal parametric combination is then evaluated by maximizing the overall grey relational grade.

In grey relational generation, the normalized data corresponding to lower-the-better (LB) criterion can be expressed as:

$$
x_{i}(k)=\frac{\max y_{i}(k)-y_{i}(k)}{\max y_{i}(k)-\min y_{i}(k)}
$$

For higher-the-better (HB) criterion, the normalized data can be expressed as:

$$
x_{i}(k)=\frac{y_{i}(k)-\min y_{i}(k)}{\max y_{i}(k)-\min y_{i}(k)}
$$

Here $x_{i}(k)$ is the value after the grey relational generation, $\min y_{i}(k)$ is the smallest value of $y_{i}(k)$ for the $k t h$ response, and $\max y_{i}(k)$ is the largest value of $y_{i}(k)$ for the $k$ th response. An ideal sequence is $x_{0}(k)$ for the responses. The purpose of grey relational grade is to reveal the degrees of relation between the sequences say, $\left[x_{0}(k)\right.$ and $\left.x_{i}(k), i=1,2,3 \ldots \ldots ., 9\right]$. The grey relational coefficient $\xi_{i}(k)$ can be calculated as

$$
\xi_{i}(k)=\frac{\Delta_{\min }+\psi \Delta_{\max }}{\Delta_{0 i}(k)+\psi \Delta_{\max }}
$$


Here $\Delta_{0 i}=\left\|x_{0}(k)-x_{i}(k)\right\|=$ difference of the absolute value $x_{0}(k)$ and $x_{i}(k) ; \psi$ is the distinguishing coefficient $0 \leq \psi \leq 1 ; \quad \Delta_{\min }=\forall j^{\min } \in i \forall k^{\min }\left\|x_{0}(k)-x j(k)\right\|=\quad$ the $\quad$ smallest $\quad$ value $\quad$ of $\Delta_{0 i} ; \quad$ and $\Delta_{\max }=\forall j^{\max } \in i \forall k^{\max }\left\|x_{0}(k)-x j(k)\right\|=$ largest value of $\Delta_{0 i}$. After averaging the grey relational coefficients, the grey relational grade $\gamma_{i}$ can be computed as:

$\gamma_{i}=\frac{1}{n} \sum_{k=1}^{n} \xi_{i}(k)$

Here $n=$ number of process responses. The higher value of grey relational grade corresponds to intense relational degree between the reference sequence $x_{0}(k)$ and the given sequence $x_{i}(k)$. The reference sequence $x_{0}(k)$ represents the best process sequence. Therefore, higher grey relational grade means that the corresponding parameter combination is closer to the optimal.

In the aforesaid study, it has been assumed that all quality features are equally important. But in practical case, it may not be so. Depending on the area of application, different response may have different preference and thereby, different tolerance limit. For example, the surface roughness and the MRR; both may be or may not be of equal importance. It depends on the decision maker. Therefore, different weightages have to be assigned to different responses. If different priority weightages have been assigned to different responses, the equation for calculating overall grey relational grade becomes:

$\gamma_{i}=\frac{\sum_{k=1}^{n} w_{k} \xi_{i}(k)}{\sum_{k=1}^{n} w_{k}}$

Here, $\gamma_{i}$ is the overall grey relational grade for ith experiment. $\xi_{i}(k)$ is the grey relational coefficient of $k t h$ response in ith experiment and $w_{k}$ is the weightage assigned to the $k$ th response.

Justification of selecting grey based Taguchi method has been explained in the work by Nandi (2009).

\section{Entropy measurement technique}

In information theory, entropy is a measure of how disordered a system is. As applying the concept of entropy to weight measurement, an attribute with a large entropy means it has a great diversity to responses so the attribute has more significant influence to the response. Recently, entropy measurement method is used to decide the weights in grey relational analysis. According to the definition proposed by Wen, Chang, and You (1998), the mapping function $f_{i}:[0,1] \rightarrow[0,1]$ used in entropy should satisfy three conditions: (1) $f_{i}(0)=0 \quad$ (2) $f_{i}(x)=f_{i}(1-x)$ and (3) $f_{i}(x)$ is monotonic increasing in the range $x \in(0,0.5)$. Thus, the following function $w_{e}(x)$ can be used as the mapping function in entropy measure.

$w_{e}(x)=x \cdot e^{(1-x)}+(1-x) e^{x}-1$

The maximum value of this function occurs at $X=0.5$, and the value is $e^{0.5}-1=0.6487$. In order to get the mapping result in the range[0,1], Wen et al. (1998) defined new entropy:

$$
W \equiv \frac{1}{\left(e^{0.5}-1\right)} \sum_{i=1}^{m} w_{e}\left(x_{i}\right)
$$

Assume there is a sequence $\epsilon_{i}=\left\{r_{i}(1), r_{i}(2), \ldots \ldots \ldots \ldots \ldots \ldots, r_{i}(n)\right\}$. Where, $r_{i}(j)$ is the grey relational coefficient. Note that $i=1,2, \ldots \ldots \ldots \ldots . . . m ; j=1,2, \ldots \ldots \ldots \ldots ., n . \quad m=$ Total number of experiments and $n=$ Total number of responses The steps for weight calculation are as follows (Wen, 2004; Datta et al., 2009). 
(a) Calculation of the sum of the grey relational coefficient in all sequences for each quality characteristic

$D_{j}=\sum_{i=1}^{m} r_{i}(j), j=1,2, \ldots \ldots \ldots \ldots, n$.

(b) Evaluation of the normalized coefficient

$k=\frac{1}{\left(e^{0.5}-1\right) \times m}=\frac{1}{0.6487 \times m}$

(c) Calculation of the entropy of each quality characteristics

$e_{j}=k \sum_{i=1}^{m} w_{e}\left(\frac{r_{i}(j)}{D_{j}}\right), \quad j=1,2, \ldots \ldots \ldots \ldots \ldots, n$.

Here, $w_{e}(x)=x \cdot e^{(1-x)}+(1-x) e^{x}-1$

(d) Calculation of the sum of entropy

$E=\sum_{j=1}^{n} e_{j}$

(e) Calculation of the weight of each quality characteristic:

$w_{j}=\frac{1}{n-E} \cdot \frac{\left[1-e_{j}\right]}{\sum_{j=1}^{n} \frac{1}{n-E} \cdot\left[1-e_{j}\right]}$, here, $j=1,2, \ldots \ldots \ldots \ldots \ldots . . ., n$.

\section{Optimization of surface roughness and MRR in end milling process}

Experimental data of $R_{a}$ value and MRR (material removal rate) corresponding to $L_{9}$ OA design of experiment has been tabulated below (Table 2). Experimental data have been normalized first (grey relational generation), shown in Table 3. For surface roughness (LB) and for MRR (HB) criterion has been used (equation (a) and (b) respectively).

Table 2: Experimental design and collected response data

\begin{tabular}{c|ccc|cc}
\hline \multirow{3}{*}{ S1. No. } & \multicolumn{3}{|l|}{ Parametric combination (Design of experiment) } & \multicolumn{2}{l}{ Response features } \\
\cline { 2 - 6 } & $\begin{array}{l}\text { Spindle Speed } \\
(\mathrm{rpm})\end{array}$ & $\begin{array}{l}\text { Feed rate } \\
(\mathrm{mm} / \mathrm{min})\end{array}$ & $\begin{array}{l}\text { Depth of Cut } \\
(\mathrm{mm})\end{array}$ & $\begin{array}{l}\mathrm{R}_{\mathrm{a}} \\
(\mu \mathrm{m})\end{array}$ & $\begin{array}{l}\mathrm{MRR} \\
\left(\mathrm{mm}^{3} / \mathrm{min}\right)\end{array}$ \\
\hline 1 & 300 & 30 & 0.2 & 1.167 & 62.500 \\
2 & 300 & 50 & 0.5 & 1.544 & 229.743 \\
3 & 300 & 70 & 0.8 & 1.720 & 428.803 \\
4 & 450 & 30 & 0.5 & 0.9696 & 133.076 \\
5 & 450 & 50 & 0.8 & 1.541 & 304.770 \\
6 & 450 & 70 & 0.2 & 1.210 & 148.200 \\
7 & 600 & 30 & 0.8 & 1.250 & 172.811 \\
8 & 600 & 50 & 0.2 & 1.000 & 116.400 \\
9 & 600 & 70 & 0.5 & 1.44 & 338.680 \\
\hline
\end{tabular}


Table 3: Normalized response values (grey relational generation) and quality loss estimates

\begin{tabular}{|c|c|c|c|c|}
\hline \multirow{2}{*}{ Sl. No. } & \multicolumn{2}{|c|}{ Response values (normalized) } & \multicolumn{2}{c|}{ Quality loss estimates } \\
\cline { 2 - 5 } & $\mathrm{R}_{\mathrm{a}}$ & $\mathrm{MRR}$ & $\mathrm{R}_{\mathrm{a}}$ & MRR \\
\hline Ideal sequence & 1.0000 & 1.0000 & 0.0000 & 0.0000 \\
\hline 1 & 0.7369 & 0.0000 & 0.2631 & 0.0000 \\
\hline 2 & 0.2345 & 0.4566 & 1.0000 & 0.5434 \\
\hline 3 & 0.0000 & 1.0000 & 0.0000 & 0.0000 \\
\hline 4 & 1.0000 & 0.1927 & 0.7615 & 0.3386 \\
\hline 5 & 0.2385 & 0.6614 & 0.3204 & 0.7660 \\
\hline 6 & 0.6796 & 0.2340 & 0.3737 & 0.6989 \\
\hline 7 & 0.6263 & 0.3011 & 0.0405 & 0.8529 \\
\hline 8 & 0.9595 & 0.1471 & 0.6269 & 0.2460 \\
\hline 9 & 0.3731 & 0.7540 & & \\
\hline
\end{tabular}

Table 3 also represents quality loss estimates of individual responses. Grey relational coefficients of individual responses have been calculated using equation (c), and tabulated in Table 4. From the knowledge of literature distinguishing coefficient has been selected as 0.5 . Table 5 represents overall grey relational grade (using equation (e)) for three sets of response weightages. In case 1, equal priority has been given to both roughness value and MRR. In case 2,75\% importance has been given to roughness value; and rest $25 \%$ for MRR. Similarly in case 3, roughness is assigned a weightage of 0.25 and for MRR priority weight is 0.75 .

Table 4: Grey relational coefficients of individual responses

\begin{tabular}{ccc}
\hline \multirow{2}{*}{ S1. No. } & \multicolumn{2}{c}{ Response values (normalized) } \\
\cline { 2 - 3 } & $\mathrm{R}_{\mathrm{a}}$ & $\mathrm{MRR}$ \\
\hline 1 & 0.6552 & 0.3333 \\
2 & 0.3951 & 0.4792 \\
3 & 0.3333 & 1.0000 \\
4 & 1.0000 & 0.3825 \\
5 & 0.3964 & 0.5962 \\
6 & 0.6095 & 0.3949 \\
7 & 0.5723 & 0.4170 \\
8 & 0.9251 & 0.3696 \\
9 & 0.4437 & 0.6702 \\
\hline
\end{tabular}

Table 5: Overall grey relational grade and predicted optimal setting

\begin{tabular}{cccc}
\hline \multirow{2}{*}{ S1. No. } & Case 1 & Case 2 & Case 3 \\
\cline { 2 - 4 } & $w_{1}=w_{2}=0.5$ & $w_{1}=0.75, w_{2}=0.25$ & $w_{1}=0.25, w_{2}=0.75$ \\
\hline 1 & 0.4943 & 0.5747 & 0.4138 \\
2 & 0.4372 & 0.4161 & 0.4582 \\
3 & 0.6667 & 0.5000 & 0.8333 \\
4 & 0.6912 & 0.8456 & 0.5369 \\
5 & 0.4963 & 0.4463 & 0.5463 \\
6 & 0.5022 & 0.5558 & 0.4486 \\
7 & 0.4947 & 0.5335 & 0.4559 \\
8 & 0.6473 & 0.7862 & 0.5084 \\
9 & 0.5570 & 0.5003 & 0.6136 \\
\hline Optimal setting & A3 B3 C2 & A2 B1 C1 & A1 B3 C3 \\
\hline Rank of factors & 2(A), 1(B), 3(C) & 3(A), 2(B), 1(C) & $3(\mathrm{~A}), 1(\mathrm{~B}), 23(\mathrm{C})$ \\
\hline
\end{tabular}

Optimal factor setting for the aforesaid three case studies have been shown in Table 5. These have been evaluated from Figure 2, 3 and 4 respectively. It has been observed that the optimal factorial combination is sensitive to the individual response weights. But assignment of these weights highly depends on the decision maker. Therefore, it seems necessary to propose a tool which can estimate these response weights mathematically so as to avoid variation of optimal setting due to various setting of response priorities defined by the decision maker.

In view of the above fact, the study proposes application of entropy measurement technique for systematic calculation and strategic evaluation of individual response weights. The evaluation procedure is given in detail. 


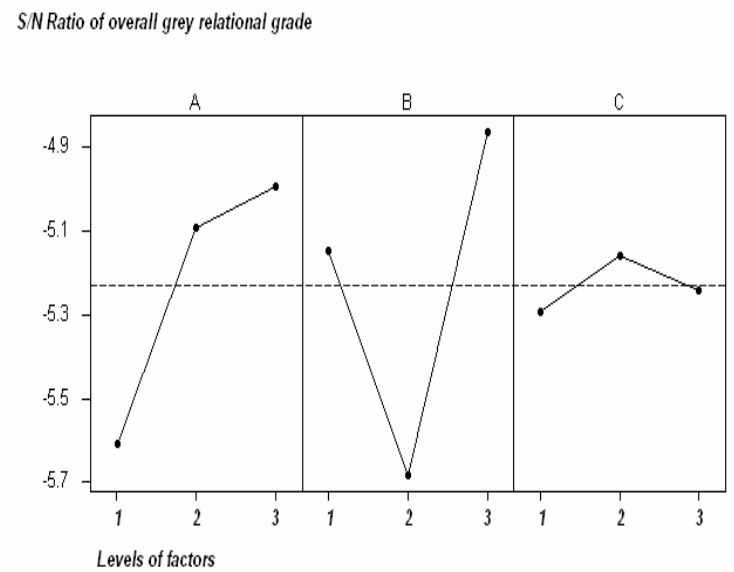

Figure 2: S/N Ratio plot for evaluation of optimal setting (Case 1)

S/N Ratio of overall grey relational grade

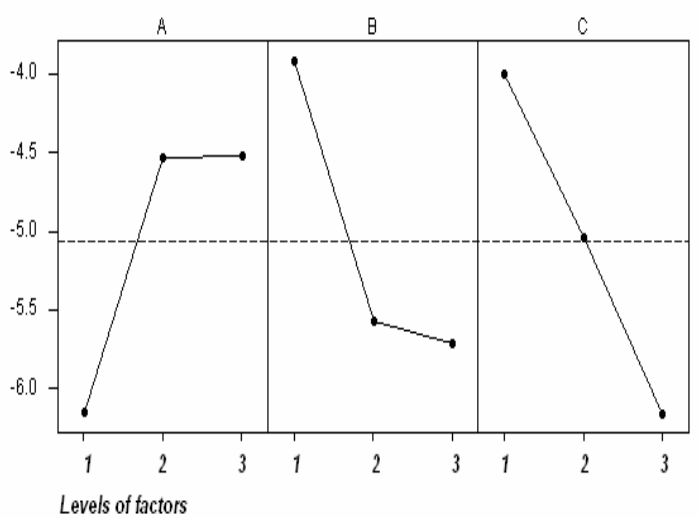

Figure 3: S/N Ratio plot for evaluation of optimal setting (Case 2)

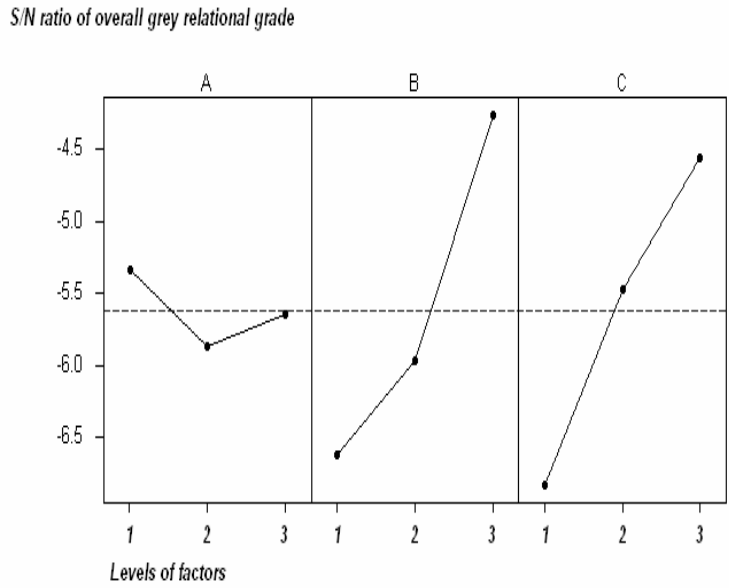

Figure 4: S/N Ratio plot for evaluation of optimal setting (Case 3)

The sum of grey relational coefficients $D_{j}, j=1,2$ for both surface roughness and MRR, have been calculated using equation (h). These are shown in Table 6. The value of the normalized coefficient has been calculated using equation (i). In the present case, $m=9$. Calculated value of the normalized coefficient becomes $k=0.1713$. 
Table 6: Calculation of $D_{j}$ (Sum of grey relational coefficients)

\begin{tabular}{cc}
\hline \multicolumn{2}{c}{ Sum of grey relational coefficients of each responses } \\
\hline Surface roughness & MRR \\
\hline 5.3306 & 4.6429 \\
\hline
\end{tabular}

Table 7: Calculation of $\left(\frac{r_{i}(j)}{D_{j}}\right)$

\begin{tabular}{ccc}
\hline & & $\left(\frac{r_{i}(j)}{D_{j}}\right)$ \\
S1. No. & & \\
\cline { 2 - 3 } & Surface roughness & MRR \\
\hline 1 & 0.1229 & 0.0718 \\
2 & 0.0741 & 0.1032 \\
3 & 0.0625 & 0.2154 \\
4 & 0.1876 & 0.0824 \\
5 & 0.0744 & 0.1284 \\
6 & 0.1143 & 0.0851 \\
7 & 0.1074 & 0.0898 \\
8 & 0.1735 & 0.0796 \\
9 & 0.0832 & 0.1443 \\
\hline
\end{tabular}

The values of $\left(\frac{r_{i}(j)}{D_{j}}\right)$ and $k \times w_{e}\left(\frac{r_{i}(j)}{D_{j}}\right)$ for surface roughness and MRR have been furnished in Table 7 and 8 , respectively. Entropy of the responses has been calculated using equation (j); the values have been furnished in Table 9. The sum of entropy $E=0.7966$ has been calculated using equation (k). The individual response weights (Table 9) have been calculated using equation (1). It has been found that both surface roughness and MRR are equally important $w_{1}=w_{2}=0.5$. It corresponds to Case 1. The overall grey relational grade has been calculated using equation (e), shown in Table 5 earlier. Thus, multi-criteria optimization problem has been transformed into a single objective optimization problem using the combination of Taguchi approach and grey relational analyses. Higher is the value of grey relational grade, the corresponding factor combination is said to be close to the optimal. The optimal factor combination as evaluated using (Figure 2) is A3 B3 C2. After evaluating the optimal setting, confirmatory test has been conducted. It showed satisfactory results. At optimal setting, experimentally obtained value of overall grey relational grade became more compared to Taguchi's prediction.

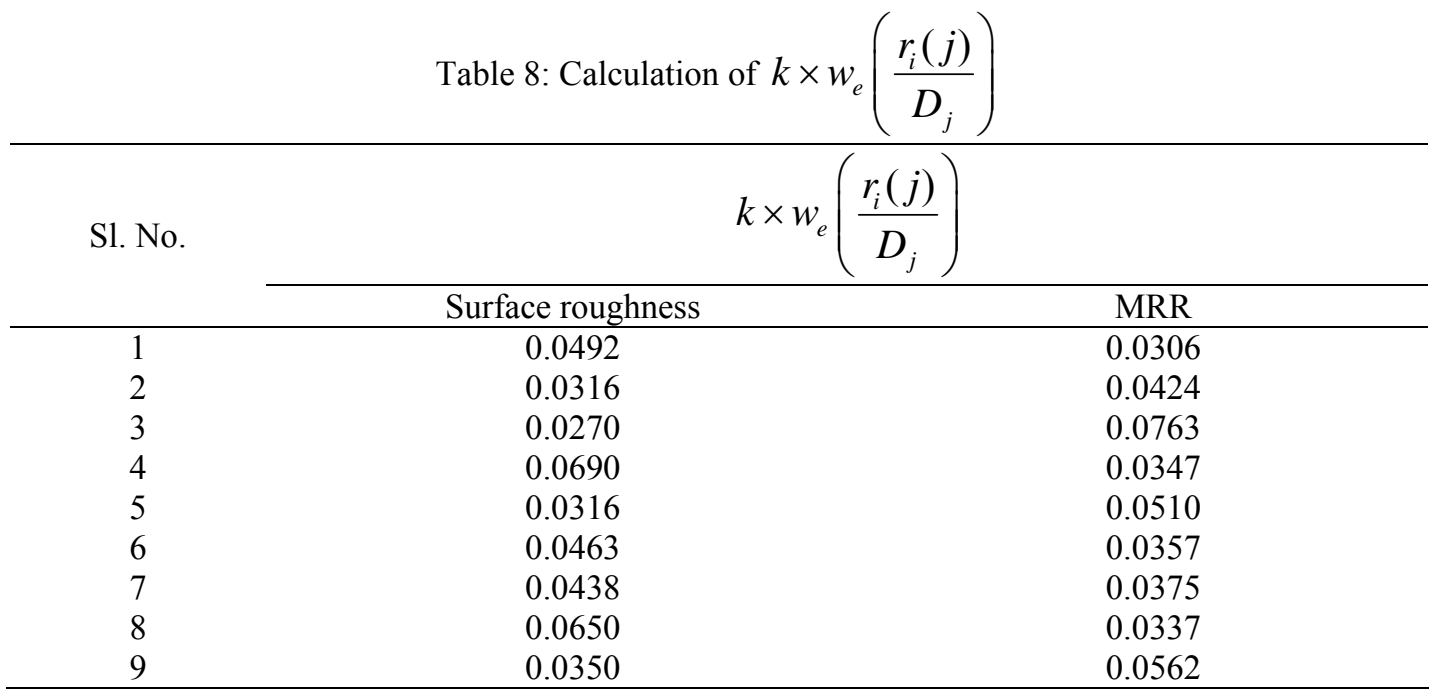


Table 9: Calculation of $e_{j}$ (entropy of each quality indexes)

\begin{tabular}{cc}
\hline \multicolumn{2}{c}{ Entropy of each responses } \\
\hline Surface roughness & MRR \\
\hline 0.3985 & 0.3981 \\
\hline
\end{tabular}

Table 10: Calculation of $w_{j}$ (weightage value of each quality characteristics)

\begin{tabular}{cc}
\hline \multicolumn{2}{c}{ Response weights } \\
\hline Priority weight of surface roughness $\left(w_{1}\right)$ & Priority weight MRR $\left(w_{2}\right)$ \\
\hline 0.50 & 0.50 \\
\hline
\end{tabular}

\section{Conclusions}

The foregoing study deals with multi-criteria optimization of CNC end milling by applying grey based Taguchi method. Application of grey relation theory is recommended to convert multiple objectives into a single objective function (overall grey relational grade) to facilitate exploration of Taguchi method. Traditional Taguchi method cannot solve a multi-objective optimization problem. That is why in the present work Taguchi method has been integrated with grey relation theory. Entropy measurement technique has been proposed to calculate individual response weights according to their relative priority. The integrated technique adapted in the present study may be efficiently applied for continuous quality improvement and off-line quality control of process not only $\mathrm{CNC}$ end milling but also any other machining operations where multiple objectives (responses) come under consideration.

In the said research it has been assumed that all responses are independent i.e. uncorrelated. But in practice this assumption may deviate. How to tackle this situation seems really a challenging task. There exists enough scope to continue research in this particular direction. Moreover, interaction effect of process parameters may also be considered in future work.

\section{References}

Alauddin M., El Baradie M.A. and Hashmi M.S.J., 1995. Computer aided analysis of a surface roughness model for end milling, Journal of Material Processing Technology, Vol. 55, pp. 123-127.

Dae Kyun Baek, Tae Jo Ko and Hee Sool Kim, 1997. A dynamic surface roughness model for face milling, Precision Engineering, Vol. 20, pp. 171-178.

Fuh Kuang-Hua and $\mathrm{Wu}$ Chiu-Fu, 1995. A proposed statistical model for surface quality prediction in end milling of Al alloy, International Journal of Machine Tools \& Manufacturing, Vol. 35, No. 8, pp. 1187-1200.

Ki Yong Lee, Myeong Chang Kang, Yung Ho Jeong, Deuk Woo Lee and Jeong Suk Kim, 2001. Simulation of surface roughness and profile in high-speed end milling, Journal of Material Processing Technology, Vol. 113, pp. 410-415.

Tsai Yu-Hsuan, Chen Joseph C. and Lou Shi-Jer, 1999. An in-process surface recognition system based on neural networks in end milling cutting operations, International Journal of Machine Tools \& Manufacturing, Vol. 39, pp. 583-605.

Benardos P.G. and Vosniakos G.C., 2002, Prediction of surface roughness in CNC face milling using neural networks and Taguchi's design of experiments, Robotics and Computer Integrated Manufacturing, Vol. 18, pp. 343 - 354.

Ozcelik B. and Bayramoglu M., 2006, The statistical modeling of surface roughness in high-speed flat end milling, International Journal of Machine Tools \& Manufacturing, Vol. 46, pp. 1395-1402.

Back D.K., Ko T.J. and Kim H.S., 2001, Optimization of feed rate in a face milling operation using a surface roughness model, International Journal of Machine Tools \& Manufacturing, Vol. 41, pp. 451-462.

Alauddin M., El Baradie M.A. and Hashmi M.S.J., 1997. Prediction of tool life in end milling by response surface methodology, Journal of Material Processing Technology, Vol. 71, pp. 456-465.

Yang L. John and Chen C. Joseph, 2001. A systematic approach for identifying optimum surface roughness performance in endmilling operations, Journal of Industrial Technology, Vol. 17, pp.1-8.

Ghani J.A., Choudhury I.A. and Hassan H.H., 2004. Application of Taguchi method in the optimization of end milling parameters, Journal of Material Processing Technology, Vol. 145, pp. 84-92.

Mansour A. and Abdalla H., 2002. Surface roughness model for end milling: a semi-free cutting carbon casehardening steel (EN32) in dry condition, Journal of Material Processing Technology, Vol. 124, pp. 183-191.

Reddy N., Kumar S. and Rao P. Venkateswara, 2006. Experimental investigation to study the effect of solid lubricants on cutting forces and surface quality in end milling, International Journal of Machine Tools \& Manufacturing, Vol. 46, pp. 189-198.

Colak O., Kurbanoglu C. and Kayacan M.C., 2007. Milling surface roughness prediction using evolutionary programming methods, Materials and Design, Vol. 28, pp. 657-666.

Oktem H., Erzurumlu T. and Kurtaran H., 2005. Application of response surface methodology in the optimization of cutting conditions for surface roughness, Journal of Material Processing Technology, Vol. 170, pp. 11-16. 
Lou M.S., Chen J.C. and Li C.M., 1999. Surface roughness prediction technique for CNC end-milling, Journal of Industrial Technology, Vol. 15, No. 1, pp. 1-6.

Fuh K.H. and Chang H.Y., 1997. An accuracy model for the peripheral milling of aluminum alloys using response surface design, Journal of Material Processing Technology, Vol. 72, pp. 42-47.

Kopac J. and Krajnik P., 2007. Robust design of flank milling parameters based on grey-Taguchi method, Journal of Material Processing Technology, pp. 1-4.

Wen K.L., Chang T.C. and You M.L., 1998. The grey entropy and its application in welding analysis, IEEE International Conference on Systems, Man, and Cybernetics, Vol. 2, pp. 1842-1844.

Wen K.L., 2004. Grey system: Modeling and prediction, Yang's Scientific Press, Tucson.

Datta S., Nandi G. and Bandyopadhyay A, 2009. Application of entropy measurement technique in grey based Taguchi method for solution of correlated multiple response optimization problems: A case study in welding, Journal of Manufacturing Systems, (in press) DOI: 10.1016/j.jmsy.2009.08.001.

Mahapatra S.S. and Chaturvedi, V., 2009, Modeling and analysis of abrasive wear performance of composites using Taguchi approach, International Journal of Engineering, Science and Technology, Vol. 1, No. 1, pp. 123-135.

Nandi G., 2009, Development of robust methodology for multi-response optimization and off-line quality control in submerged arc welding, Ph. D. Thesis, Jadavpur University, Kolkata.

Moshat S., Datta S., Bandyopadhyay A. and Pal P.K., 2010, Optimization of CNC end milling process parameters using PCA based Taguchi method, International Journal of Engineering, Science and Technology, Vol. 2, No. 1, pp. 92-102.

\section{Biographical notes}

Mr. Sanjit Moshat is an Ex. P. G. scholar of Department of Mechanical Engineering, Jadavpur University, Kolkata, India. He did his M. E. in Production Engineering from Jadavpur University in the year 2007.

Dr. Saurav Datta $(*)$ is an Assistant Professor in the Department of Mechanical Engineering, National Institute of Technology Rourkela India. He obtained his BME (Hons), and PhD degrees in Mechanical Engineering from Jadavpur University. He has more than 6 years of experience in teaching and research. His current area of research includes Welding Technology, Manufacturing Processes, Multi-Criteria Decision-Making, Quality Engineering, optimization \& Simulation modeling.

Dr. Asish Bandyopadhyay is a Professor of the Department of Mechanical Engineering, Jadavpur University, Kolkata, India. He has been serving at the university for the last 23 years. He completed his undergraduate and postgraduate studies in Mechanical Engineering and was awarded PhD (Engg) degree from Jadavpur University. Before joining Jadavpur University, he served in heavy industries in India for approximately six years. His fields of interest include manufacturing and machining technology and heat transfer.

Dr. Pradip Kumar Pal is presently a Professor of the Department of Mechanical Engineering, Jadavpur University, India. He obtained his BME (Hons), MME and PhD degrees in Mechanical Engineering from Jadavpur University. He has been involved with teaching and research since 1985 at said university. His teaching and research areas include manufacturing science, machine tool vibration and welding technology.

Received December 2009

Accepted January 2010

Final acceptance in revised form February 2010 